\title{
How Portuguese and American teachers plan for literacy instruction
}

\section{Louise Spear-Swerling, Joao Lopes, Celia Oliveira \& Jamie Zibulsky}

\section{Annals of Dyslexia}

An Interdisciplinary Journal of The International Dyslexia Association

ISSN 0736-9387

Ann. of Dyslexia

DOI 10.1007/s11881-015-0107-x

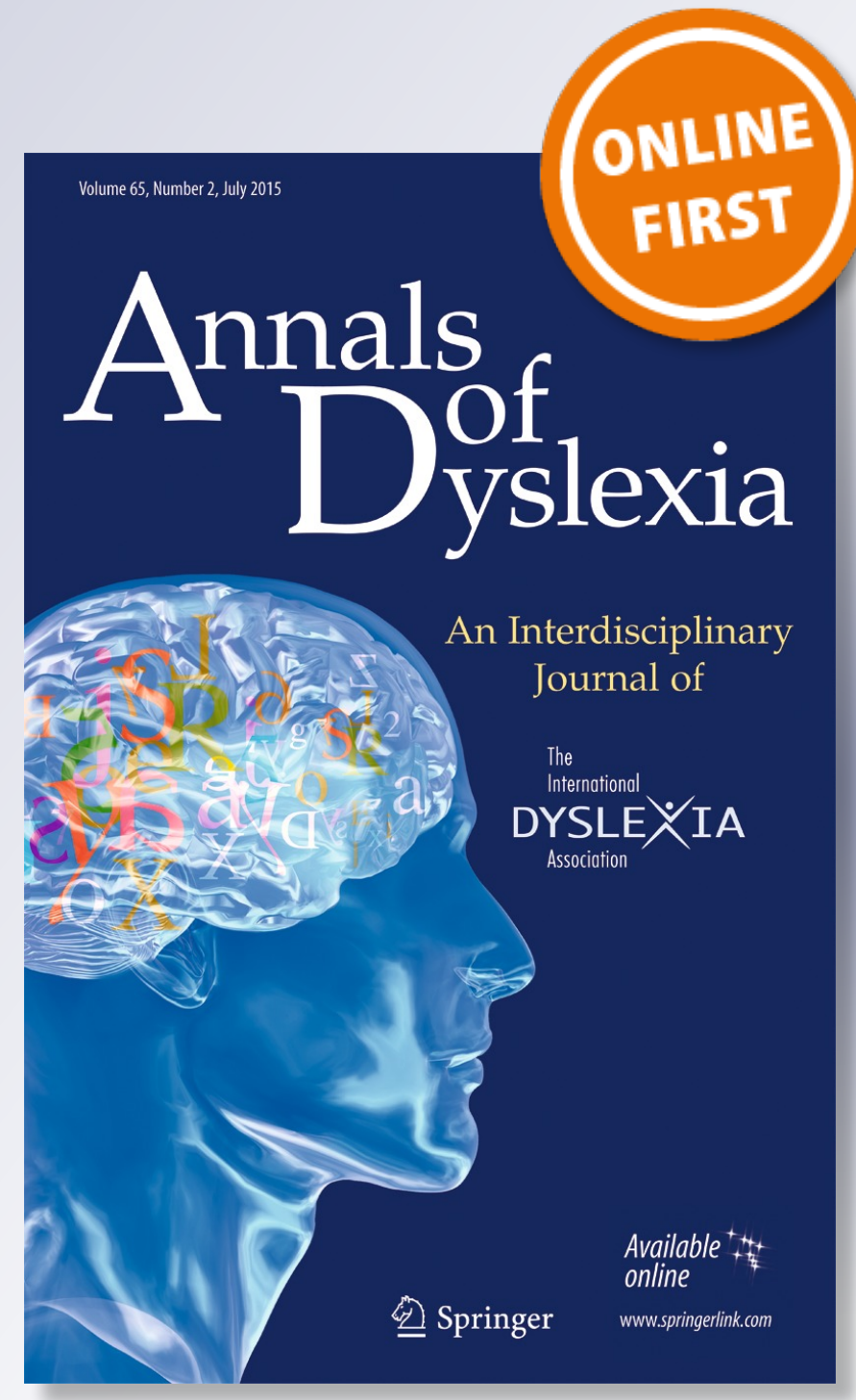

Springer 
Your article is protected by copyright and all rights are held exclusively by The International Dyslexia Association. This e-offprint is for personal use only and shall not be selfarchived in electronic repositories. If you wish to self-archive your article, please use the accepted manuscript version for posting on your own website. You may further deposit the accepted manuscript version in any repository, provided it is only made publicly available 12 months after official publication or later and provided acknowledgement is given to the original source of publication and a link is inserted to the published article on Springer's website. The link must be accompanied by the following text: "The final publication is available at link.springer.com". 


\title{
How Portuguese and American teachers plan for literacy instruction
}

\author{
Louise Spear-Swerling $^{1} \cdot$ Joao $_{\text {Lopes }}^{2} \cdot$ Celia Oliveira $^{3}$ • \\ Jamie Zibulsky ${ }^{4}$
}

Received: 8 February 2015 / Accepted: 16 June 2015

(C) The International Dyslexia Association 2015

\begin{abstract}
This study explored American and Portuguese elementary teachers' preferences in planning for literacy instruction using the Language Arts Activity Grid (LAAG; Cunningham, Zibulsky, Stanovich, \& Stanovich, 2009), on which teachers described their preferred instructional activities for a hypothetical 2-h language arts block. Portuguese teachers $(N=186)$ completed Portuguese versions of a background questionnaire and LAAG electronically, in Survey Monkey; American teachers $(N=102)$ completed identical English measures using paper and pencil. Results showed that teachers in both groups usually addressed comprehension and reading fluency on their LAAGs and that they also allocated the most time to these two areas. However, American teachers were more likely to include teacher-directed fluency activities, whereas Portuguese teachers were more likely to include fluency activities that were not teacher directed. Significantly more American than Portuguese teachers addressed phonics in their planning, whereas significantly more Portuguese than American teachers addressed writing processes such as revision. Both groups of educators demonstrated large variability in planning, with many teachers omitting important components of literacy identified by researchers, for writing as well as reading. The study highlights the importance of providing teachers with comprehensive, research-based core literacy curricula as well as professional development on key components of literacy. Study findings also suggest significant relationships between orthographic transparency and teachers' instructional planning.
\end{abstract}

Louise Spear-Swerling

SPEARSWERLL1@southernct.edu

1 Department of Special Education and Reading, Southern Connecticut State University, 501 Crescent St., New Haven, CT 06515, USA

2 School of Psychology, Department of Applied Psychology, University of Minho, Campus de Gualtar, 4710-057 Braga, Portugal

3 Lusófona University of Porto, Rua Augusto Rosa, no 24, 4000-098 Porto, Portugal

4 Psychology Department, T-WH1-01, Fairleigh Dickinson University, 1000 River Road, Teaneck, NJ 07666, USA 
Keywords Cross-linguistic · Reading · Teacher beliefs · Teacher education · Teacher knowledge · Writing

Effective teaching, by knowledgeable teachers who believe children can succeed, is important to the literacy attainment of students across the globe. Even so, a comparison of literacy teachers in different countries may be useful for multiple reasons. First, although considerable research on the knowledge base and beliefs of American educators teaching reading in English has emerged over the past couple of decades (e.g., Bos, Mather, Dickson, Podhajski, \& Chard, 2001; Brady et al., 2009; Cunningham, Perry, Stanovich, \& Stanovich, 2004; Cunningham, Zibulsky, Stanovich, \& Stanovich, 2009; McCutchen, Green, Abbott, \& Sanders, 2009; Moats, 1994; Moats \& Foorman, 2003; Spear-Swerling, 2015; Spear-Swerling \& Brucker, 2004; Spear-Swerling \& Cheesman, 2012), comparable research concerning educators who teach reading in other languages and other countries is scant. This kind of research could help inform teacher preparation and professional development in those other countries as well as the U.S.A. Furthermore, English varies from other languages in some important ways that may make generalizations based on research conducted solely in English-speaking countries misleading (Share, 2008). Comparisons of educators who teach different languages in different countries (e.g., Lopes, Spear-Swerling, Oliveira, Velasquez, \& Zibulsky, 2014) can help highlight important variables for study in future research focused on teacher knowledge and beliefs about literacy instruction. In this study, we compared teachers' planning of a hypothetical literacy instructional block, using a task designed as a measure of teacher knowledge and beliefs, in educators from two countries, the U.S.A. and Portugal.

\section{Learning to read: English and Portuguese}

Many research studies and reviews of children learning to read in English have emphasized the importance of certain component abilities for children's reading development in the elementary grades. In English, important component reading abilities include phonemic awareness, phonics (word decoding), fluent reading of text, vocabulary knowledge, and comprehension of language beyond the single-word level (National Reading Panel [NRP], 2000; National Research Council [NRC], 1998; Rand Reading Study Group, 2002; Scarborough, 2002; Stanovich, 2000). A particular component ability is not necessarily equally important at all grade levels. For example, for typical children learning to read English, phonemic awareness tends to be central to reading development in kindergarten and early grade 1, and less central after that, because past grade 1, typical readers have already developed the level of phonemic awareness needed to decode printed words successfully (O'Connor, 2011). Nevertheless, a weakness in a single component that is vital at a particular stage of reading development may seriously derail a child's overall reading progress.

Alphabetic orthographies such as English have been classified along a continuum of transparent to opaque (or shallow to deep) writing systems. Transparent orthographies have straightforward and highly predictable letter-sound mappings, whereas opaque orthographies have more complex mappings (Duncan et al., 2013). English is a highly opaque writing system and in this respect differs from many other, more transparent orthographies, such as Spanish, Finnish, Italian, and German. In general, however, it appears that all alphabetic writing systems require most if not all of the same component reading abilities. Children learning to read transparent orthographies do not recruit completely different component abilities than do those 
learning to read English, although the former do appear to move more quickly through the early stages of reading development than the latter (Vaessen et al., 2010).

Portuguese is considered an alphabetic orthography of intermediate depth, somewhat more opaque than Spanish or Italian, but significantly less opaque than English (Duncan et al., 2013; Sucena, Castro, \& Seymour, 2009). Component abilities such as phonemic awareness, letter-sound knowledge, decoding skill, and reading fluency have all been found relevant to Portuguese children's reading acquisition; however, young Portuguese readers seem to develop accurate decoding skills more rapidly than do typical English readers (e.g., Cardoso-Martins, 1995; Fernandes, Ventura, Querido, \& Morais, 2008; Lopes, Silva, Spear-Swerling, \& Zibulsky, 2015; Sucena et al., 2009; Vaessen et al., 2010). Still, even in orthographies more transparent than English, including Portuguese, phonics instruction has an important influence on children's ability to manipulate phonemes (Duncan et al., 2013), which may also affect their acquisition of reading skills.

\section{Learning to write: English and Portuguese}

Children's writing development also involves specific component writing abilities. Four types of abilities are frequently highlighted in research on learning to write in English (e.g., Berninger et al., 2006; Ehri, 1997; Graham, Harris, \& Fink, 2000; Graham, MacArthur, \& Fitzgerald, 2007; Olinghouse \& Wilson, 2012). These abilities are spelling; other basic writing skills such as handwriting, grammar, capitalization, and sentence structure; abilities related to text composition (sometimes termed text generation) such as word choice, text organization, and knowledge about genre and discourse structure; and writing processes. Examples of important writing processes include planning a piece of writing, revising content, and editing for mistakes in basic writing skills. As in the case of reading, a particular component writing skill may be relatively more important at some grade levels than others. For instance, it is likely that writing processes such as planning and revision are relatively more important in later grades, as children are expected to produce increasingly lengthy, complex pieces of writing, than in the earliest grades. In addition, specific component writing abilities and corresponding components of reading tend to interact and be mutually facilitative. Spelling words and decoding them tap similar underlying abilities, and instruction in one area can help to reinforce the other (Joshi, Treiman, Carreker, \& Moats, 2008/2009; Moats, 2005/2006). Similarly, abilities related to text composition such as knowledge about word choice and text structure facilitate reading comprehension as well as written expression (Graham \& Hebert, 2010).

Research on children's writing development in Portuguese is relatively limited, but the component writing areas outlined above appear to play important roles in Portuguese as well as English writing development. For example, Limpo and Alves (2013) found that, in a sample of upper elementary and middle-school Portuguese children, component writing abilities such as spelling, handwriting, and planning processes contributed directly or indirectly (depending on grade level) to text generation.

\section{Influence of literacy instruction and literacy policy}

Explicit instruction in important components of literacy influences children's literacy development significantly. Struggling readers, struggling writers, and at-risk children generally 
benefit from explicit, systematic teaching of the components of literacy in which they are weak (e.g., Aaron, Joshi, Gooden, \& Bentum, 2008; Spear-Swerling, 2015). Furthermore, including instruction in the components essential to literacy development at a given grade level may help to prevent the emergence of literacy difficulties in many children (Fletcher, Lyon, Fuchs, \& Barnes, 2007; Foorman, Francis, Fletcher, Schatschneider, \& Mehta, 1998). Researchers have not identified ideal instructional time allocations for specific component reading or writing abilities; moreover, what is "ideal" probably varies both by grade level and by population, with some groups of children benefiting from relatively heavier emphases in certain areas than others. For instance, research on children in the U.S.A. who are learning to read English as a second language indicates that these children tend to benefit from an increased instructional emphasis on English vocabulary and academic language, because they are especially likely to lack prior exposure to these areas (August \& Shanahan, 2006). When comparing children learning to read different alphabetic languages, orthographic depth is another factor to consider. Children learning to read relatively shallow orthographies may need less time for phonics or spelling instruction than do those learning to read and spell a highly opaque writing system such as English. Nevertheless, for all children, complete omission of a component vital to reading or writing development at their grade level is likely to be problematic, as is an excessive focus on a single component, which may crowd out attention to other essential components.

American literacy policy An important set of influences on literacy instruction involves state and national policy on literacy. In the U.S.A., two policies that have affected literacy teaching in recent years involve multi-tiered systems of support (MTSS) sometimes termed response-to instruction (RTI) approaches to teaching literacy, and the Common Core State Standards (CCSS; Council of Council of Chief State School Officers [CCSSO] \& National Governors' Association [NGA], 2010). MTSS models (e.g., Brown-Chidsey \& Steege, 2005; Fuchs, Fuchs, \& Vaughn, 2008; Spear-Swerling, 2015) emphasize research-based, comprehensive literacy teaching in general education, coupled with universal screening to identify atrisk students early, and with prompt intervention for all at-risk students. Although most MTSS models and research studies have focused on reading, these models have also been applied to writing (e.g., Berninger \& Abbott, 2003; Hooper et al., 2013).

The CCSS provide a consistent set of national standards for literacy and mathematics in the U.S.A. As of this writing, the English/language arts standards of the Common Core have been adopted by 46 out of 50 states. The development of the CCSS was spurred in part by research suggesting that many American students are not well prepared academically for college or the careers of a global economy (Adams, 2012). The standards aim to increase rigor in academic expectations as well as the complexity of texts that American students can read, understand, and write. Concerns have been raised about certain limitations and potential unintended consequences of the standards (e.g., Hiebert \& Mesmer, 2013; Moats, 2012), but the CCSS do include all the components of reading and writing previously mentioned, by grade level, for the $\mathrm{K}-12$ range. Taken together, these two policies have led to an increased focus on researchbased literacy instruction and accountability in the U.S.A., with widespread use of summative assessments now increasingly based on the Common Core, as well as formative assessments aimed at early identification of and intervention for reading problems.

Portuguese literacy policy In Portugal, two recent policies have had some impact on the literacy instruction of teachers in elementary schools. The first is the National Reading Plan 
(Plano Nacional de Leitura, 2007). This governmental plan was developed because of general concerns about Portugal's literacy level, as well as specific concerns regarding the poor performance of Portuguese students on international examinations (e.g., on the Programme for International Student Assessment [PISA]). The main goals of the National Reading Plan were to strengthen students' reading habits as well as their literacy achievement; however, this policy is more widely known for emphasizing reading habits than reading or writing skills. The second significant policy involves Curricular Standards for the Portuguese Language (Metas Curriculares de Português, 2012). Like the CCSS in the U.S.A., the Curricular Standards attempt to specify which student competencies should be addressed by grade level; for instance, they establish benchmarks for the number of words per minute that a student is expected to read by the end of Grade 1 through the end of Grade 6. Both Portuguese policies have been developed in a context in which the systematic assessment of student progress in national and international examinations has become a political and educational priority (Lopes \& Almeida, 2015). The main difference between these two policies is that the Curricular Standards are legally enforced, and therefore their influence on teachers' daily practices will likely be stronger. However, because the standards are relatively recent, their full impact is still uncertain.

\section{Previous research on teacher knowledge and beliefs for literacy instruction}

Unfortunately, both in the U.S.A. and Portugal, the policy measures discussed in the previous section do not appear to be associated with widespread improvements in teacher knowledge about research-based reading instruction. For example, many studies of U.S. elementary teachers, both general and special educators, have indicated that these educators often lack knowledge about English word structure, such as being able to identify individual phonemes in words, common syllable types, or phonetically irregular words (e.g., Cunningham et al., 2004; Moats \& Foorman, 2003; Spear-Swerling \& Brucker, 2004). Moreover, educators often do not understand key components of reading development such as phonemic awareness or the role of accurate and automatic decoding in learning to read (e.g., Brady et al., 2009; Moats \& Foorman, 2003; Spear-Swerling \& Cheesman, 2012). In Portugal, the scientific literature on reading is less extensive than in the U.S.A. (Lopes, 2010). However, a study that compared the knowledge base of Portuguese and American teachers for teaching reading (Lopes et al., 2014) found that the Portuguese educators performed at significantly lower levels than the American educators, especially on questions that tapped their knowledge about research-based practices for assessment and intervention.

Many other variables besides teacher knowledge are important for effective reading instruction. High levels of teacher knowledge alone do not guarantee improved student outcomes (Carlisle, Correnti, Phelps, \& Zheng, 2009; Carlisle, Kelcey, Rowan, \& Phelps, 2011; Piasta, Connor, Fishman, \& Morrison, 2009). Still, findings of serious limitations in teacher knowledge are alarming. These kinds of findings suggest that knowledge about reading that is very well established in the scientific community is not reaching educators - and without knowledgeable teachers, these findings are unlikely to fully benefit children. Furthermore, although almost no studies have explored teachers' knowledge base for writing instruction, the findings on reading do not bode well for writing, an area that typically receives much less emphasis than reading in both $\mathrm{K}-12$ instruction and teacher professional development (Graham \& Hebert, 2010; National Commission on Writing, 2003). 
A few U.S. studies have explored teachers' proposed time allocations in instructional planning, which serve as an indicator of teachers' beliefs about what is important in reading instruction. Cunningham et al. (2009) developed a measure called the Language Arts Activity Grid (LAAG) to study first-grade teachers' proposed time allocations for a hypothetical 2-h English/language arts instructional block, a common time frame for literacy instruction in the U.S.A.. They found that many first-grade teachers planned to allocate time in ways inconsistent with research-based recommendations, proposing to spend only a few minutes on average on key components of reading as phonemic awareness and vocabulary, and to spend virtually no time on assessment, despite the importance of formative assessment for planning instruction. Spear-Swerling and Zibulsky (2014) used a modified version of the LAAG to study the proposed time allocations of a group of K-5 American educators in literacy instruction. Their results were globally similar to those of Cunningham et al. (2009), but extended them to teachers beyond Grade 1. In addition, the study showed that important components of writing as well as reading tended to receive short shrift in teachers' proposed time allocations.

The goal of the present study was to extend research on teachers' instructional planning for literacy to a comparison of Portuguese and American elementary-level educators. The main questions of the study were these: (1) Would Portuguese and American teachers differ in their inclusion of important components of reading and written expression on LAAGs? (2) Would teachers' planning in either country reflect research-based recommendations for literacy instruction?

\section{Method}

\section{Participants}

The American and Portuguese teachers were a subgroup of participants from a larger study (Lopes et al., 2014) of teachers' knowledge and beliefs for reading instruction, all of whom had completed LAAGs relevant to the elementary grades. Table 1 displays the background characteristics of participants from each country.

American sample The American sample involved 102 participants (89 female, 13 male) from two different states in the Northeastern part of the U.S.A. All of the participants were elementary-level educators licensed to teach reading as part of their certifications. Forty-four percent (44\%) of the American sample held a Masters degree in education or a related field. Teachers in the American sample were relatively young (mean age $=34.2$ years, $\mathrm{SD}=10.6$ ) and

Table 1 Background characteristics of study participants $(N=288)$

\begin{tabular}{lll}
\hline Characteristic & $\begin{array}{l}\text { American educators }(n=102) \\
\text { Mean (SD) }\end{array}$ & $\begin{array}{l}\text { Portuguese educators }(n=186) \\
\text { Mean (SD) }\end{array}$ \\
\hline Age (in years) & $34.2(10.6)$ & $42.2(8.9)$ \\
Years of teaching experience & $9.0(9.8)$ & $18.0(9.7)$ \\
Gender & Percentage of group & Percentage of group \\
Masters degree & $87 \% \mathrm{~F}, 13 \% \mathrm{M}$ & $91 \% \mathrm{~F}, 9 \% \mathrm{M}$ \\
\hline
\end{tabular}


had an average of 9-years' experience teaching reading (mean=9.0 years, $\mathrm{SD}=9.8$ ). They were recruited both from university and public school settings. Participants from university settings came from graduate-level education classes in which most participants were working toward Masters degrees. Those from public school settings were recruited as part of in-service professional development programs.

Portuguese sample The Portuguese sample involved 186 participants (170 female, 16 male) from a nationally representative sample of Portuguese teachers. Portuguese participants were recruited entirely from school-based settings. All participants held the necessary credentials to teach at the elementary level, but as compared to the American sample, fewer held a Masters degree (i.e., $9 \%$ vs. $44 \%$ for the Americans). Also, the Portuguese teachers were older on average than were the American teachers (mean age=42.2 years, $\mathrm{SD}=8.9$ ), and they had more experience teaching reading (mean years of teaching $=18.0$ years, $\mathrm{SD}=9.7$ ) than did the American educators. Mann-Whitney $U$ tests showed that the differences in all three background variables (age, years of teaching experience, and proportion of teachers with a Masters degree) were statistically significant at the $p<.001$ level.

\section{Materials and procedure}

All participants completed a background questionnaire and the LAAG, both originally developed in English and translated into Portuguese equivalents for the Portuguese sample. (Please see Spear-Swerling \& Zibulsky, 2014, for further detail about the development of the English measures.) The American participants were tested in groups using paper-and-pencil versions of the measures, whereas the Portuguese participants completed the measures on Survey Monkey. Both groups of teachers completed the measures anonymously, with total administration time for the two measures involving about one hour. Both groups also completed the measures in the same order, with the background questionnaire first.

The background questionnaire elicited information about participants' ages, teaching credentials, educational background, degrees, and years of experience teaching reading at the elementary level. The LAAG used in the present study was modeled after the one employed by Cunningham et al. (2009) and Spear-Swerling and Zibulsky (2014). Participants were presented with an open grid, on which they were asked to indicate the grade they currently or had most recently taught, and then to specify the activities they would utilize in a 2-h English/ language arts instructional block for that grade. Participants were told to be as specific as possible in describing activities as well as to indicate the number of minutes they would allocate to each activity. Directions for the LAAG noted that participants should plan activities as they thought best for the children, not necessarily on the basis of how their school districts might want them to plan. All of the participants in the current study planned LAAGs that summed to $120 \mathrm{~min}$ and completed LAAGs within the kindergarten to Grade 5 range (for the American teachers) or within the Grade 1 through Grade 4 range (for the Portuguese teachers).

The investigators developed a detailed codebook in advance for the LAAG, using modified versions of the codebooks employed by Cunningham et al. (2009) and Spear-Swerling and Zibulsky (2014). All writing activities were coded into one of four categories. These categories were spelling; basic writing skills other than spelling (e.g., handwriting, capitalization, punctuation, grammar, sentence structure); writing processes (e.g., planning, revision, editing); and text composition (e.g., content and organization of writing beyond the sentence level). With 
regard to reading activities, virtually all activities that involved phonemic awareness were done in combination with phonics activities, especially for the Portuguese sample, so differentiating the two as separate areas was often difficult. Hence, a combined category for phonemic awareness and phonics was employed in all analyses.

Most of the other categories of the present study were similar or identical to those used by Cunningham et al. (2009) and Spear-Swerling and Zibulsky (2014), including assessment, vocabulary, oral and reading comprehension, teacher-directed reading fluency activities (e.g., guided oral reading with a teacher), and non-teacher-directed fluency activities (e.g., independent silent reading). A "not codable" category also was established for LAAG descriptions that could not be reliably coded. These kinds of descriptions included those too vague to assign to a category or those in which the participant simply named a commercial program without further detail. For both the Portuguese and American teachers, the number of minutes in this category was relatively small, although there was considerable variability in both groups. The mean number of not codable minutes for the American teachers was $11.2(\mathrm{SD}=16.1)$ and for the Portuguese teachers it was 9.7 ( $\mathrm{SD}=17.6)$, with no significant differences between the two groups of teachers.

For both samples, a subset of LAAGs (about $50 \%$ ) was dually coded by two of the investigators, or by an investigator and a research assistant, with all inconsistencies resolved prior to completion of data coding. The Appendix displays the coding categories of the current study along with examples of activities for each category.

\section{Results}

Most analyses described in this section employed dichotomous coding on the LAAG, in which participants who had planned any amount of time at all for a category, no matter how little, were coded with a "1," and those who had not included the category at all on the LAAG were assigned a " 0 ." We emphasized this liberal approach to coding, rather than number of minutes planned by participants, because it is difficult to accurately determine how much time is sufficient for specific components, especially for two different languages that vary in orthographic transparency. However, descriptive data on the number of minutes planned by participants for various LAAG categories also is included and analyzed below.

In addition, we considered the number of reading components and the number of writing components that participants addressed. For reading, the maximum number of components that participants could include on their LAAGs was four (phonemic awareness/phonics, reading fluency, vocabulary, comprehension). Participants received credit for addressing reading fluency regardless of which type of activity they used, teacher directed or not. For written expression, the maximum number of components also was four (spelling, basic writing skills other than spelling, writing processes, and text composition).

\section{Correlations}

The first set of analyses examined nonparametric (Spearman's rho) correlations of the background variables (age, presence or absence of a Masters, and years of teaching experience) with the variables involving dichotomous coding of the LAAG categories, as well as with the total number of reading and writing components addressed. Separate sets of correlations were done for the American participants and for the Portuguese participants. 
For the American sample, all of the significant correlations were positive. Age correlated significantly with the inclusion of spelling $(r=.208, p<.05)$ and other basic writing skills $(r=.258, p<.05)$ on LAAGs. Age also correlated with the total number of writing components on the LAAG $(r=.259, p<.01)$, but not with the number of reading components. Similarly, having a Masters degree correlated with including teacher-directed reading fluency activities on the LAAG $(r=.254, p<.05)$, spelling $(r=.228, p<.05)$ and with text composition $(r=.216$, $p<.05)$. Again, participants with Masters degree tended to include more writing components $(r=.278, p<.01)$, but not more reading components, than did teachers without a Masters. Years of teaching experience correlated significantly with inclusion of teacher-directed reading fluency $(r=.273, p<.01)$, spelling $(r=.239, p<.05)$, writing-other basic skills $(r=.298$, $p<.01)$ and text composition $(r=.215, p<.05)$, as well as with total number of writing components addressed on the LAAG $(r=.334, p<.01)$. Overall, then, in the American sample, older teachers with a Masters degree and relatively high levels of teaching experience were more likely than younger, less experienced teachers without Masters degrees to plan teacherdirected reading fluency activities on their LAAGs as well as to address multiple components of writing.

For the Portuguese educators, the patterns of correlations were somewhat different. Age correlated negatively with the inclusion of spelling activities on the LAAG, $r=-.225, p<.01$; no other relationships between age and LAAG variables were significant. Years of teaching experience also correlated negatively with inclusion of spelling activities on LAAGs $(r=-.203$, $p<.01$ ). Thus, unlike the American teachers, Portuguese educators who were older and more experienced were significantly less likely to plan spelling activities on the LAAGs. For the Portuguese teachers, having a Masters degree correlated significantly with only one of the LAAG categories, inclusion of teacher-directed reading fluency activities $(r=.217, p<.01)$.

Finally, as one would expect, age and teaching experience correlated significantly and positively for both groups of educators. However, the pattern of relationships associated with having a Masters degree was different for the two groups. For the American sample, the older, more experienced teachers were more likely to have Masters degrees, whereas for the Portuguese sample, there were no relationships between having a Masters and age or teaching experience. This may reflect the fact that attaining a Masters degree has been required of Portuguese educators only since 2007, whereas this requirement has been more longstanding for American educators.

\section{Specific categories included on LAAGs for American and Portuguese teachers}

To compare American and Portuguese teachers' inclusion of specific categories on their LAAGs, we wanted groups that were as similar as possible in age and years of teaching experience, as well as on the grade level of LAAG they had completed. (Unfortunately we were unable to match groups on presence or absence of Masters degrees due to the small number of Portuguese participants in our sample who held a Masters.) To attain a sufficient number of LAAGs for analysis, we compared participants at two composite levels: Grades 1 and 2 versus Grades 3 and 4. This approach yielded 38 Grade 1 or 2 LAAGs for the Americans and 92 for the Portuguese educators, as well as 34 Grade 3 or 4 LAAGs for the Americans and 94 for the Portuguese teachers. For Grade 1 and 2 LAAGs, we then compared the 38 Portuguese teachers most similar in years of teaching experience and age to the 38 Americans, and did the same for the 34 Portuguese and American educators who had completed Grade 3 and 4 LAAGs. 
The above approach yielded groups with comparable mean ages and years of experience. For Grade 1 and 2 LAAGs, the Portuguese teachers' mean age was 36.3 years $(\mathrm{SD}=8.6)$ and mean years of experience was $10.7(\mathrm{SD}=8.6)$; for the Americans the respective means were $33.2(\mathrm{SD}=10.7)$ and $8.4(\mathrm{SD}=10.6)$. For the Grade 3 and 4 LAAGs, the Portuguese teachers' mean age was $37.7(\mathrm{SD}=8.7)$ and mean experience was $12.9(\mathrm{SD}=9.4)$, with the respective means for the Americans $36.8(\mathrm{SD}=12.9)$ and $11.4(\mathrm{SD}=11.0)$. None of the mean differences in age or years of teaching experience were significant at either composite grade level. Table 2 displays the percentage of Portuguese and American teachers for each composite grade level who addressed specific categories of activities on their LAAGs, including significant differences between teacher groups within each composite level as determined by chi-square tests.

Grade 1 and 2 LAAGs As shown in the second and third columns of Table 2, the most frequently included LAAG category for both Portuguese and American educators who completed Grade 1 and 2 LAAGs was comprehension, with exactly the same percentage of educators $(76.3 \%)$ in both groups addressing this area. The two groups, $68.4 \%$ of the Portuguese sample and $57.9 \%$ of the American sample, also often included activities for reading fluency that were not teacher directed, with no significant differences across groups. Both groups of teachers addressed spelling and vocabulary infrequently on their LAAGs, with $26.3 \%$ of Americans and $13.2 \%$ of Portuguese teachers addressing spelling, and $23.7 \%$ of Americans and $18.4 \%$ of Portuguese teachers addressing vocabulary, again with no significant group differences.

However, Portuguese educators who completed LAAGs for Grade 1 or 2 were much more likely than the American educators to include activities for assessment $(34.2 \%$ of the Portuguese teachers vs. $2.6 \%$ of the Americans, $p<.001$ ), basic writing skills other than spelling $(57.9 \%$ vs. $13.2 \%, p<.001)$, and writing processes such as planning or revision $(23.7$ $\%$ vs. $0 \%, p<.01)$. Conversely, the American educators were significantly more likely than were the Portuguese teachers to include activities that addressed phonemic awareness/phonics

Table 2 Percentage of participants who included specific LAAG categories $(N=144)$

\begin{tabular}{|c|c|c|c|c|}
\hline \multirow[b]{2}{*}{ LAAG category } & \multicolumn{2}{|c|}{ Grade 1 and 2 LAAGs } & \multicolumn{2}{|c|}{ Grade 3 and 4 LAAGs } \\
\hline & $\begin{array}{l}\text { American \% } \\
(n=38)\end{array}$ & $\begin{array}{l}\text { Portuguese \% } \\
(n=38)\end{array}$ & $\begin{array}{l}\text { American \% } \\
(n=34)\end{array}$ & $\begin{array}{l}\text { Portuguese \% } \\
(n=34)\end{array}$ \\
\hline Assessment & $2.6^{* * *}$ & $34.2 * * *$ & 11.8 & 20.6 \\
\hline Phonemic awareness/phonics & $65.8^{* *}$ & $31.6^{* *}$ & $26.5^{*}$ & $2.9^{*}$ \\
\hline Comprehension & 76.3 & 76.3 & 70.6 & 91.2 \\
\hline Vocabulary & 23.7 & 18.4 & 32.4 & 35.3 \\
\hline Reading fluency-TD & $76.3^{* * *}$ & $34.2 * * *$ & $64.7 * * *$ & $17.6^{* * *}$ \\
\hline Reading fluency-NTD & 57.9 & 68.4 & $55.9 * * *$ & $97.1 * * *$ \\
\hline Spelling & 26.3 & 13.2 & $41.2^{*}$ & $11.8^{*}$ \\
\hline Writing - other basic skills & $13.2 * * *$ & $57.9 * * *$ & 52.9 & 52.9 \\
\hline Writing-processes & $0 * *$ & $23.7 * *$ & $2.9 * * *$ & $50 * * *$ \\
\hline Writing - text composition & $50 *$ & $23.7^{*}$ & 61.8 & 50 \\
\hline
\end{tabular}

$T D$ teacher directed; $N T D$ not teacher directed

$* p<.05, * * p<.01, * * * p<.001$ 
$(65.8 \%$ vs. $34.2 \%, p<.01)$, teacher-directed reading fluency $(76.3 \%$ vs. $34.2 \%, p<.001)$, and text composition $(50 \%$ vs. $23.7 \%, p<.05)$.

Grade 3 and 4 LAAGs As shown in the two far-right columns of Table 2, for the Grade 3 and 4 LAAGs, comprehension was again frequently included by both Portuguese and American teachers; $91.2 \%$ of the Portuguese teachers and $70.6 \%$ of the American teachers addressed comprehension, with the differences between groups marginally significant $(p=.06)$. However, Portuguese teachers who completed LAAGs for Grade 3 or 4 were significantly more likely than American teachers to include reading fluency activities that were not teacher directed (97.1\% of Portuguese educators vs. $55.9 \%$ of American educators, $p<.001)$ and to address writing processes (50\% vs. $2.9 \%, p<.001)$. Conversely, American educators who completed Grade 3 or 4 LAAGs were significantly more likely than the Portuguese teachers to include activities involving phonemic awareness/phonics $(26.5 \%$ vs. $2.9 \%, p<.05)$, teacher-directed reading fluency $(64.7 \%$ vs. $17.6 \%, p<.001)$, and spelling $(41.2 \%$ vs. $11.8 \%, p<.05)$. The two groups of teachers did not differ significantly with regard to inclusion of assessment activities (20.6\% of Portuguese teachers and $11.8 \%$ of the American sample), vocabulary activities (35.3\% of Portuguese teachers and $32.4 \%$ of Americans), other basic writing skills besides spelling (52.9 \% for both groups of teachers), and text composition activities (included by $50 \%$ of the Portuguese and $61.8 \%$ of the American educators).

To sum up, the comparisons of Portuguese and American teachers of similar mean ages and teaching experience showed that across both composite grade levels, both groups usually included activities aimed at comprehension and at reading fluency. However, the types of fluency activities tended to differ, with the Portuguese teachers often including activities that were not teacher directed, especially in Grade 3 and 4 LAAGs, and the American teachers more frequently including teacher-directed fluency activities. For both composite grade levels, the American teachers were also more likely to include activities aimed at phonemic awareness/phonics, and the Portuguese educators more likely to include activities aimed at writing processes. Other differences between groups held only for one composite level and not the other. For Grade 1 and 2 LAAGs, the Portuguese educators were much more likely than the American teachers to address assessment and basic writing skills other than spelling, whereas the Americans were more likely than the Portuguese sample to address text composition in Grade 1 and 2 LAAGs. For Grade 3 and 4 LAAGs, the American teachers were more likely than the Portuguese teachers to include activities involving spelling.

\section{Number of minutes planned for each LAAG category}

Another set of analyses focused upon the mean number of minutes participants planned for each LAAG category. These analyses employed the same educator groups and composite LAAG grade levels described in the previous section. The results of these analyses are displayed in Table 3, along with statistically significant differences between educator groups as determined by Mann-Whitney $U$ tests.

As Table 3 shows, the overall patterns of results for mean number of minutes, including patterns of significant differences, mirror those involving dichotomous coding of LAAG categories displayed in Table 2. Both groups of teachers, for both composite grade levels, 
Table 3 Mean number of minutes planned for specific LAAG categories $(N=144)$

\begin{tabular}{|c|c|c|c|c|}
\hline \multirow[b]{3}{*}{ LAAG category } & \multicolumn{2}{|c|}{ Grade 1 and 2 LAAGs } & \multicolumn{2}{|c|}{ Grade 3 and 4 LAAGs } \\
\hline & $\begin{array}{l}\text { American \% } \\
(n=38)\end{array}$ & $\begin{array}{l}\text { Portuguese \% } \\
(n=38)\end{array}$ & $\begin{array}{l}\text { American \% } \\
(n=34)\end{array}$ & $\begin{array}{l}\text { Portuguese \% } \\
(n=34)\end{array}$ \\
\hline & Mean (SD) & Mean (SD) & Mean (SD) & Mean (SD) \\
\hline Assessment & $0.3(1.6)^{* * *}$ & $7.0(12.3)^{* * *}$ & $2.6(7.9)$ & $5.0(10.5)$ \\
\hline Phonemic awareness/phonics & $17.4(15.4)^{* *}$ & $11.2(22.9)^{* *}$ & $4.2(7.5)^{* *}$ & $0.2(1.0)^{* *}$ \\
\hline Comprehension & $26.8(25.7)$ & $36.2(33.8)$ & $28.0(32.4)^{*}$ & $43.5(29.5)^{*}$ \\
\hline Vocabulary & $4.2(8.4)$ & $5.2(16.1)$ & $5.1(8.3)$ & $5.9(9.4)$ \\
\hline Reading fluency-TD & $22.1(19.7)^{* * *}$ & $5.8(9.2)^{* * *}$ & $20.1(17.8)^{* * *}$ & $1.9(4.6)^{* * *}$ \\
\hline Reading fluency $-\mathrm{NTD}$ & $13.9(14.2)$ & $22.2(19.5)$ & $14.8(15.4)^{* *}$ & $26.3(15.3)^{* *}$ \\
\hline Spelling & $4.1(7.8)$ & $4.5(13.0)$ & $6.5(8.6)^{* *}$ & $2.0(6.6)^{* *}$ \\
\hline Writing_other basic skills & $2.9(8.7)^{* * *}$ & $16.8(18.2)^{* * *}$ & $11.6(13.5)$ & $12.7(16.1)$ \\
\hline Writing_processes & $0(0)^{* *}$ & $8.9(19.8)^{* *}$ & $1.2(6.9)^{* * *}$ & $17.4(19.9)^{* * *}$ \\
\hline Writing-text composition & $14.1(16.7)^{*}$ & $8.9(19.8)^{*}$ & $15.9(14.2)$ & $17.4(19.9)$ \\
\hline
\end{tabular}

$T D$ teacher directed, $N T D$ not teacher directed

$* p<.05, * * p<.01, * * * p<.001$

allocated the most minutes to comprehension and reading fluency activities. However, the American teachers planned significantly more minutes for teacher-directed fluency activities, whereas the Portuguese teachers planned more minutes for fluency activities that were not teacher directed. For both composite grade levels, the American teachers planned significantly more minutes than the Portuguese teachers for phonemic awareness/phonics activities, whereas the Portuguese educators planned significantly more minutes for writing processes than did the Americans. Both groups of teachers allocated little time to vocabulary or spelling activities, less than 7 min on average for each area. For the Grade 1 and 2 LAAGs, the American teachers allocated significantly more minutes to text composition, whereas the Portuguese teachers planned significantly more minutes for basic writing skills; in the Grade 3 and 4 LAAGs, these differences in time allocation between teacher groups were not significant. As in the analyses that employed dichotomous coding, the differences for number of minutes allocated to assessment were significant only for the Grade 1 and 2 LAAGs, with the Portuguese teachers allocating significantly more time to this area than the American teachers.

Several interesting findings emerge from the analyses involving number of minutes. First, as illustrated by the standard deviations in Table 3, both groups of teachers showed great variability in the number of minutes they planned for most categories, with some teachers planning no time at all in an area and others planning a substantial amount of time. In addition, for both composite grade levels, the Portuguese teachers planned more minutes for comprehension activities than did the American teachers, with these differences attaining significance for the Grade 3 and 4 LAAGs. Finally, some differences by teacher group, though significant in both sets of analyses (the ones involving categories addressed and the ones involving mean amounts of time allocated), nevertheless did not involve large amounts of time on average. For example, although the American educators were significantly more likely 
than the Portuguese teachers to address the phonemic awareness/phonics category in Grade 3 and 4 LAAGs, and although they allocated significantly more time to this area than did the Portuguese teachers, the mean number of minutes that the Americans allocated at this composite grade level was only 4.2. Conversely, although the Portuguese teachers were significantly more likely than the American educators to include assessment activities in Grade 1 and 2 LAAGs, and although they planned significantly more minutes for this area than did the Americans, the mean number of minutes the Portuguese teachers planned was only 7.0.

\section{Number of components addressed by American and Portuguese teachers}

The final set of analyses focused simply on the number of components of literacy for which teachers planned, rather than the type of components as examined in the previous analyses. This set of analyses used the entire sample of educators. As discussed in the Introduction, certain components of literacy are much more relevant to children's development (at least in relation to typical students' development) at some grade levels than others. Still, many components of literacy are relevant throughout all or most of the $\mathrm{K}-5$ range, including vocabulary, comprehension, reading fluency, basic writing skills, and text composition. Moreover, despite the differences in orthographic transparency between English and Portuguese, all of the aforementioned components are relevant in both languages. Thus, if teachers in both groups understood important components of literacy, we expected that they would address multiple components in their LAAGs, perhaps five or more.

Table 4 shows the number of components of literacy included by both groups of teachers on their LAAGs. The two groups did not vary significantly in the number of components they addressed for either reading or writing. Both groups of teachers addressed on average slightly more than two components of reading and slightly more than one component of writing, for a total of approximately three and a half components of literacy altogether.

It is equally important to note that there was large variability in teachers' planning, particularly in the area of writing. Twenty-six of the American teachers (25\%) and 56 of the Portuguese teachers $(30 \%)$ did not include any writing activity on their LAAGs. In addition, 14 of the American teachers (14\%) and 39 of the Portuguese teachers $(21 \%)$ planned activities for no more than a single component of reading. Encouragingly, some teachers in both samples did plan for multiple components of literacy in their hypothetical English/language arts blocks, five components or more, but only a minority of teachers did so in each sample (29\% of the American teachers and $25 \%$ of the Portuguese teachers).

Table 4 Number of components of literacy addressed in LAAGs $(N=288)$

\begin{tabular}{lll}
\hline Type of component & $\begin{array}{l}\text { American educators }(n=102) \\
\text { Mean }(\mathrm{SD})\end{array}$ & $\begin{array}{l}\text { Portuguese educators }(n=186) \\
\text { Mean }(\mathrm{SD})\end{array}$ \\
\hline Reading $(\max =4)$ & $2.35(.83)$ & $2.23(.80)$ \\
Writing $(\max =4)$ & $1.27(1.01)$ & $1.28(1.14)$ \\
Total $(\max =8)$ & $3.63(1.32)$ & $3.51(1.33)$ \\
\hline
\end{tabular}




\section{Discussion}

\section{Answers to the study questions}

The analyses suggest the following answers to the questions posed at the outset of the study. First, Portuguese and American teachers did differ in their planning on LAAGs in numerous ways. For each composite grade level, both groups of educators usually planned activities for comprehension and reading fluency. However, the American sample more often included teacher-directed reading fluency activities whereas (especially on Grade 3 and 4 LAAGS) the Portuguese sample more often included fluency activities that were not teacher directed, such as independent silent reading. In addition, for both composite grade levels, significantly more American than Portuguese educators included activities in the combined category of phonemic awareness/phonics. There were also noteworthy differences between the two groups of educators in multiple areas of writing. For both composite grade levels, significantly more Portuguese than American teachers included activities aimed at writing processes, with differences especially large for Grade 3 and 4 LAAGs. In Grade 1 and 2 LAAGs, American educators were more likely than Portuguese educators to include activities aimed at text composition, whereas for these grades the Portuguese educators were more likely to include activities for basic writing skills (as well as writing processes). Significantly more American than Portuguese educators addressed spelling in Grade 3 and 4 LAAGs. Finally, the Portuguese educators were more likely than the Americans to include assessment activities on their LAAGs, especially for Grades 1 and 2, although the mean amount of time they allocated to assessment was relatively small.

With regard to the second question of the study, many teachers in both samples did not plan in ways consistent with research-based recommendations. Although Portuguese and American educators differed in the type of literacy components they addressed, they did not differ in the overall number of components they included on their LAAGs, for either reading or writing. Furthermore, consistent with previous studies involving the LAAG (Cunningham et al., 2009; Spear-Swerling \& Zibulsky, 2014), both groups of teachers varied widely in the mean amounts of time they allocated to key components of literacy. Meta-analyses, consensus reports, and research reviews (e.g., Berninger et al., 2006; Graham \& Hebert, 2010; Graham et al., 2007; NRP, 2000; NRC, 1998) have emphasized multiple components of writing as well as multiple components of reading, and the two hours of instructional time involved in the LAAG task is a substantial amount of time for teaching multiple components of literacy. Nevertheless, in the current study only a minority of both groups, less than a third of teachers, addressed all or even most of the components relevant to the LAAG grade level for which they planned. Furthermore, a quarter of the American sample and nearly a third of the Portuguese sample did not address any components of writing, and other participants addressed just one or two components of reading. To put it another way, in both groups, many educators appeared to lack a componential understanding of literacy, in relation to writing as well as reading.

Teachers in both groups frequently omitted specific components that have been highlighted as important in research. For example, for both composite grade levels, the majority of Portuguese and American educators failed to include any vocabulary activities on their LAAGs. Vocabulary is a key area to address in literacy instruction, especially for certain atrisk populations such as children from poverty or language-minority backgrounds (August \& Shanahan, 2006). Likewise, although researchers in the area of writing (e.g., Berninger et al., 2006; Graham \& Hebert, 2010; Graham et al., 2007) have emphasized the importance of both 
writing processes and foundational skills such as spelling to students' writing, almost none of the American educators addressed writing processes in their planning, and only a minority of the Americans addressed spelling. Even when teachers did address vocabulary or spelling, the amount of time they allocated to these areas was usually quite small.

Indeed, a third of the Grade 1 and 2 LAAGs in the American sample completely omitted phonemic awareness/phonics, despite the overwhelming research consensus on the importance of this area for early reading (NRC, 1998; NRP, 2000; Stanovich, 2000). In an actual classroom context, these omissions would be highly problematic for beginning readers in general, and particularly so for children who are prone to decoding problems, such as those with dyslexia. Portuguese children with dyslexia also tend to have difficulties that involve phonology (Pacheco et al., 2014). Limited attention to areas such as phonemic awareness/ phonics and spelling among the Portuguese teachers in the study would likely be problematic for these children as well. Due to the relative transparency of the language, reading problems in Portuguese often manifest as difficulties with fluency rather than accuracy of decoding (Lopes, 2010), but accurate decoding is an essential foundation for fluency development (Ehri, 1997; NRP, 2000). Inattention to phonics in beginning reading instruction could therefore contribute to some Portuguese children's reading or spelling difficulties - again, especially in those who have a vulnerability to these kinds of problems.

\section{Limitations}

Important limitations of the study included small sample size at each LAAG grade level that necessitated the use of composite grade levels in analyses. There were also background differences in teacher samples that could not be completely eliminated in the analyses, especially differences in educational level; many more of the American teachers than the Portuguese teachers held Masters degrees. It is possible that certain differences between teacher groups - such as in the use of teacher-directed reading fluency activities, which was associated with having a Masters degree for both the American and Portuguese participants - might be reduced or eliminated had we been able to compare more closely matched groups of teachers. In addition, the study involved a planning task, not actual classroom observations of teachers. We also did not evaluate the quality of teachers' planned activities and whether they were research based. If quality of activities was considered, the results of the study would probably be even more extreme, because not all participants who addressed a particular category on the LAAG planned activities that were research based.

\section{Conclusions and implications}

Many Portuguese and American educators seemed to lack a componential understanding of literacy. Both groups of teachers often omitted important components of literacy in their planning or allocated very small amounts of time for certain components. Still, there were some notable differences between the two groups in the areas they chose to include on the planning task and in their time allocations for different categories. Some of these differences, such as the relatively greater emphasis of the American educators on the areas of phonemic awareness/phonics, spelling, and teacher-directed reading fluency, probably reflect the fact that the Americans were teaching children to read English, a significantly less transparent language than Portuguese. Portuguese is a language of intermediate depth, so these differences might be 
even greater if teachers of English were compared to those teaching reading in a very transparent orthography such as Spanish.

Other differences between teacher groups may reflect differences in educational policies or economic conditions. For example, although both countries have educational policies that emphasize assessment, these policies seem to have influenced Portuguese educators somewhat more than American educators, at least in relation to Grade 1 and 2 LAAGs. These differences in the inclusion of assessment activities may be partly related to strict evaluation policies for teachers and students in Portugal as well as economic conditions there. Specifically, in recent years Portuguese teachers have been under intense pressure to show in evaluations, from the earliest grades, that their students are meeting the Curricular Standards. Teachers whose students perform poorly in these evaluations may perceive that they can be more easily fired. Indeed, thousands of educators have lost jobs - about ten thousand in 2013 alone (Lima, 2013) - in a very depressed financial climate where there are often few job alternatives.

Yet other differences between teacher groups could reflect differences in the prevailing instructional approaches in each country. For instance, constructivist approaches to writing instruction (e.g., Calkins, 2011), which emphasize content (meaning) aspects of writing over basic skills, have been particularly influential in the U.S.A., including in the states from which the American participants came. The popularity of these approaches could account for the tendency of the American educators in our sample to address text composition aspects of writing, often through activities such as creative writing or reading response, more frequently than did the Portuguese educators, especially in Grade 1 and 2 LAAGs. (However, this explanation would not account for the Americans' surprising lack of attention to writing processes, also emphasized by constructivist approaches to writing.)

Overall, the study contributes to current research on teacher knowledge and beliefs by showing how instructional planning may differ for educators who are teaching languages that vary in orthographic transparency. It also highlights some professional needs of both groups of teachers - not only in relation to reading, but writing as well. Many of the Portuguese and American educators appeared to require professional development on the key components of literacy and on the importance of addressing those components in instruction. Furthermore, although both groups of teachers had access to comprehensive literacy standards for students (i.e., the CCSS in the U.S.A. and Curricular Standards in Portugal), standards alone were not sufficient for many educators in either group to address all of the components of literacy important at the grade levels for which they completed LAAGs. This was particularly true with regard to writing. Rather, research-based core curricula and programs in literacy that include all of the components important by grade may be essential for important components of literacy to be consistently taught. Of course, some educators in both countries did plan in ways relatively consistent with research-based recommendations. Nevertheless, there was great variability in individual educators' attention to vital areas such as phonics, vocabulary, spelling, and writing processes, as well as great variability in their time allocations for these areas. Without professional development and appropriate core literacy curricula, variability across teachers would likely affect some children's literacy progress. The negative impact would be greatest for the most vulnerable readers and writers in a school, including not only those with constitutionally based learning disabilities, but also those with more experientially based literacy problems, such as language-minority students or children with limited preschool literacy exposure.

Variability in individual educators' attention to important components of literacy could also greatly undermine the implementation of MTSS approaches and the CCSS 
in the U.S.A., as well as Curricular Standards in Portugal. High-quality literacy instruction in the elementary grades that is systemic and consistent across educators-not dependent on whether a student is lucky enough to have particular teachers - is essential to achieving the aims of all of these policies. Research-based, targeted professional development for teachers, with comprehensive core literacy curricula that address all key components of literacy, will likely be necessary for these policies to achieve their intended goals, in both countries and both languages.

Acknowledgments This research was supported by a 2-year grant from the Foundation Francisco Manuel dos Santos in Portugal as well as by a Connecticut State University research grant in the U.S.A. We would like to express our sincere gratitude to these funding agencies as well as to the teachers and school districts who participated in the study and sent messages of interest about our research. In addition, warm thanks to our research assistants for their help with data collection, coding, and analysis, and to Anne Cunningham for providing us with inspiration as well as guidance in this work.

\section{Appendix}

\section{Sample Activities for Different LAAG Coding Categories}

Assessment: Testing, assessment, evaluation

Phonemic awareness and phonics: Blending sounds, sound recognition, rhyming, letter recognition, word building, structural analysis, word attack

Reading fluency - teacher directed: Reading text aloud (student reads to teacher), smallgroup reading, guided reading, round robin reading, reader's theater

Reading fluency — not teacher directed: Independent reading of text (student reads silently), SSR (Sustained Silent Reading), free choice reading, practice reading

Comprehension and oral language development: Read aloud (teacher to students), listening comprehension, reading comprehension, literature, stories, comprehension questions, comprehension strategies, graphic organizers [i.e., activities in which the primary goal was comprehension of text, orally or through the children's own reading]

Vocabulary: Oral vocabulary, vocabulary review, definitions, word meanings

Spelling: Teaching spelling, irregular word spelling, inventive spelling, spelling patterns

Writing — basic skills and conventions: Handwriting, grammar, copying sentences, capitalization, punctuation, sentence structure, sentence building

Writing-processes: Drafting, planning writing, editing, peer editing, writing process

Writing - text composition: Composition, writing response, written reports, reading response journal, paragraph writing, creative writing

Not codable: Games, reading centers, literacy centers, seatwork, computer activities, cooperative learning, small-group activities, specific commercial programs (all named without further elaboration)

\section{References}

Aaron, P. G., Joshi, M., Gooden, R., \& Bentum, K. (2008). Diagnosis and treatment of reading disabilities based on the component model of reading: An alternative to the discrepancy model of LD. Journal of Learning Disabilities, 41, 67-84.

Adams, M. J. (2012). On the importance of standards. Perspectives on Language and Literacy, 38, 11-14. 
August, D., \& Shanahan, T. (2006). Developing literacy in second-language learners: Report of the National Literacy Panel on Language-Minority Children and Youth. Mahwah, NJ: Erlbaum.

Berninger, V., \& Abbott, S. (2003). Research-supported reading and writing lessons. San Antonio, Tx: Psychological Corporation.

Berninger, V. W., Abbott, R. D., Jones, J., Gould, L., Anderson-Youngstrom, M., Shimada, S., et al. (2006). Early development of language by hand: Composing, reading, listening, and speaking connections; three letterwriting modes; and fast mapping in spelling. Developmental Neuropsychology, 29, 61-92.

Bos, C., Mather, N., Dickson, S., Podhajski, B., \& Chard, D. (2001). Perceptions and knowledge of preservice and inservice educators about early reading instruction. Annals of Dyslexia, 51, 97-120.

Brady, S., Gillis, M., Smith, T., Lavalette, M., Liss-Bronstein, L., Lowe, E., . . W Wilder, T. D. (2009). First grade teachers' knowledge of phonological awareness and code concepts: Examining gains from an intensive form of professional development. Reading and Writing: An Interdisciplinary Journal, 22, 425-455.

Brown-Chidsey, R., \& Steege, M. (2005). Response to intervention: Principles and strategies for effective practice. New York: Guilford.

Calkins, L. (2011). A curricular plan for the writing workshop. Portsmouth NH: Heinemann.

Cardoso-Martins, C. (1995). Sensitivity to rhymes, syllables, and phonemes in literacy acquisition in Portuguese. Reading Research Quarterly, 808-828.

Carlisle, J. F., Correnti, R., Phelps, G., \& Zeng, J. (2009). Exploration of the contribution of teachers' knowledge about reading to their students' improvement in reading. Reading and Writing, 22(4), 457-486.

Carlisle, J. F., Kelcey, B., Rowan, B., \& Phelps, G. (2011). Teachers' knowledge about early reading: Effects on students' gains in reading achievement. Journal of Research on Educational Effectiveness, 4, 289-321.

Council of Chief State School Officers [CCSSO] \& National Governors' Association [NGA]. (2010). Common Core State Standards for English/language arts \& literacy in history/social studies, science, \& technical subjects. Retrieved from http://www.corestandards.org/ela-literacy.

Cunningham, A. E., Perry, K. E., Stanovich, K. E., \& Stanovich, P. J. (2004). Disciplinary knowledge of K-3 teachers and their knowledge calibration in the domain of early literacy. Annals of Dyslexia, 54, 139-167.

Cunningham, A. E., Zibulsky, J., Stanovich, K. E., \& Stanovich, P. J. (2009). How teachers would spend their time teaching language arts: The mismatch between self-reported and best practices. Journal of Learning Disabilities, 42, 418-430.

Duncan, L. G., Castro, S. L., Defior, S., Seymour, P. H., Baillie, S., Leybaert, J., et al. (2013). Phonological development in relation to native language and literacy: Variations on a theme in six alphabetic orthographies. Cognition, 127(3), 398-419.

Ehri, L. C. (1997). Learning to read and learning to spell are one and the same, almost. In C. A. Perfetti, L. Rieben, \& M. Fayol (Eds.), Learning to spell: Research, theory, and practice across languages (pp. 237269). Mahwah, NJ: Erlbaum.

Fernandes, S., Ventura, P., Querido, L., \& Morais, J. (2008). Reading and spelling acquisition in European Portuguese: A preliminary study. Reading and Writing, 21(8), 805-821.

Fletcher, J. M., Lyon, G. R., Fuchs, L. S., \& Barnes, M. A. (2007). Learning disabilities: From identification to intervention. New York: Guilford.

Foorman, B. R., Francis, D. J., Fletcher, J. M., Schatschneider, C., \& Mehta, P. (1998). The role of instruction in learning to read: Preventing reading disabilities in at-risk children. Journal of Educational Psychology, 90, 37-55.

Fuchs, D., Fuchs, L., \& Vaughn, S. (2008). Response to intervention: A framework for reading educators. Newark, DE: International Reading Association.

Graham, S., Harris, K., \& Fink, B. (2000). Is handwriting causally related to learning to write? Treatment of handwriting problems in beginning writers. Journal of Educational Psychology, 92, 620-633.

Graham, S., \& Hebert, M. A. (2010). Writing to read: Evidence for how writing can improve reading. A Carnegie Corporation Time to Act Report. Washington, DC: Alliance for Excellent Education. Retrieved from http:// carnegie.org/publications/search-publications/pub/315/.

Graham, S., McArthur, C. A., \& Fitzgerald, J. (Eds.). (2007). Best practices in writing instruction. New York, NY: Guilford.

Hiebert, E. H., \& Mesmer, H. A. (2013). Upping the ante of text complexity in the Common Core State Standards: Examining its potential impact on young readers. Educational Researcher, 42, 44-51.

Hooper, S. R., Costa, L. J. C., McBee, M., Anderson, K. L., Yerby, D. C., Childress, A., et al. (2013). A written language intervention for at-risk second grade students: A randomized controlled trial of the process assessment of the learner lesson plans in a tier 2 response-to-intervention (RtI) model. Annals of Dyslexia, 63(1), 44-64.

Joshi, R.M., Treiman, R., Carreker, S., \& Moats, L. (Winter, 2008-2009). How words cast their spell. American Educator, 6-16, 42-43.

Lima, R. P. (2013). Governo avança com 20 mil despedimentos [Government fires 20 thousand people. Half are teachers], Expresso. Retrieved from http://expresso.sapo.pt/governo-avanca-com-20-mil-despedimentos= f793681. 
Limpo, T., \& Alves, R. A. (2013). Modeling writing development: Contribution of transcription and selfregulation to Portuguese students' text generation quality. Journal of Educational Psychology, 105(2), 401.

Lopes, J. A. (2010). Conceptualização, avaliação e intervenção nas dificuldades de aprendizagem: A sofisticada arquitectura de um equívoco [Conceptualization, evaluation and intervention in learning disabilities: The sophisticated architecture of a misconception]. Braga: Psiquilíbrios.

Lopes, J., \& Almeida, L. S. (2015). Questões e modelos de avaliação e intervenção em Psicologia Escolar [Assessment and intervention issues and models in School Psychology]. Estudos de Psicologia, 32(1).

Lopes, J., Silva, M. M., Spear-Swerling, L., \& Zibulsky, J. (2015). Prosody growth and reading comprehension: A longitudinal study from 2nd through end of 3rd grade. Journal of Psychodidactics, 20(1), 45-65.

Lopes, J., Spear-Swerling, L., Oliveira, C., Velasquez, M. G., \& Zibulsky, J. (2014). Actual disciplinary knowledge, perceived disciplinary knowledge, teaching experience, and teachers' training for reading instruction: a study with primary Portuguese and American teachers. Journal of Psychodidactics, 19(1), 45-65.

McCutchen, D., Green, L., Abbott, R. D., \& Sanders, E. A. (2009). Further evidence for teacher knowledge: Supporting struggling readers in grades three through five. Reading and Writing: An Interdisciplinary Journal, 22, 401-423.

Metas Curriculares de Portugues. (2012). Retrieved from http://www.dgidc.min-edu.pt/index.php?s= noticias\&noticia $=396$.

Moats, L. C. (1994). The missing foundation in teacher education: Knowledge of the structure of spoken and written language. Annals of Dyslexia, 44, 81-102.

Moats, L. C. (2005/2006). How spelling supports reading - and why it is more regular and predictable than you may think. American Educator, 12-22, 42-43.

Moats, L. C. (2012). Reconciling the common core state standards with reading research. Perspectives on Language and Literacy, 38, 15-18.

Moats, L. C., \& Foorman, B. R. (2003). Measuring teachers' content knowledge of language and reading. Annals of Dyslexia, 53, 23-45.

National Commission on Writing. (2003). The neglected " $R$ ": The need for a writing revolution. Report of the National Commission on Writing in America's schools and colleges. New York, NY: College Entrance Examination Board.

National Reading Panel. (2000). Teaching children to read: An evidence-based assessment of the scientific research literature on reading and its implications for reading instruction. Washington, DC: National Institutes of Health.

National Research Council. (1998). Preventing reading difficulties in young children. Washington, DC: National Academy Press.

O'Connor, R. E. (2011). Phoneme awareness and the alphabetic principle. In R. E. O'Connor \& P. F. Vadasy (Eds.), Handbook of reading interventions (pp. 9-26). New York: Guilford.

Olinghouse, N. G., \& Wilson, J. (2012). Strategic, meaningful, and effective writing instruction for elementary students. In M. C. Hougen \& S. M. Smartt (Eds.), Fundamentals of literacy instruction \& assessment, pre-K6 (pp. 205-224). Baltimore, MD: Brookes.

Pacheco, A., Reis, A., Araujo, S., Inacio, F., Petersson, K. M., \& Faisca, L. (2014). Dyslexia heterogeneity: Cognitive profiling of Portuguese children with dyslexia. Reading \& Writing: An Interdisciplinary Journal, 27(9), 1529-1545.

Piasta, S. B., Connor, C. M., Fishman, B. J., \& Morrison, F. J. (2009). Teachers' knowledge of literacy concepts, classroom practices, and student reading growth. Scientific Studies of Reading, 13, 224-248.

Plano Nacional de Leitura. (2007). Retrieved from www.planonacionaldeleitura.gov.pt/index1.php.

Rand Reading Study Group. (2002). Reading for understanding: Toward an $R$ \& $D$ program in reading comprehension. Santa Monica, CA: Rand.

Scarborough, H. S. (2002). Connecting early language and literacy to later reading (dis)abilities: Evidence, theory, and practice. In S. B. Neuman \& D. K. Dickinson (Eds.), Handbook of early literacy research (pp. 97-125). New York: Guilford Press.

Share, D. L. (2008). On the Anglocentricities of current reading research and practice: The perils of overreliance on an "outlier" orthography. Psychological Bulletin, 134, 584-615.

Spear-Swerling, L. (2015). The power of RTI and reading profiles: A blueprint for solving reading problems. Baltimore, MD: Brookes Publishing Co.

Spear-Swerling, L., \& Brucker, P. (2004). Preparing novice teachers to develop basic reading and spelling skills in children. Annals of Dyslexia, 54, 332-364.

Spear-Swerling, L., \& Cheesman, E. (2012). Teachers' knowledge base for implementing response-tointervention models in reading. Reading \& Writing: An Interdisciplinary Journal, 25, 1691-1723.

Spear-Swerling, L., \& Zibulsky, J. (2014). Making time for literacy: Teacher knowledge and time allocation in instructional planning. Reading \& Writing: An Interdisciplinary Journal, 27(8), 1353-1378. 
Stanovich, K. E. (2000). Progress in understanding reading: Scientific foundations and new frontiers. New York, NY: Guilford Press.

Sucena, A., Castro, S. L., \& Seymour, P. (2009). Developmental dyslexia in an orthography of intermediate depth: The case of European Portuguese. Reading and Writing, 22(7), 791-810.

Vaessen, A., Bertrand, D., Tóth, D., Csépe, V., Faísca, L., Reis, A., et al. (2010). Cognitive development of fluent word reading does not qualitatively differ between transparent and opaque orthographies. Journal of Educational Psychology, 102(4), 827. 